\title{
ANÁLISE DA REPRESENTAÇÃO FEMININA NA CÂMARA DOS DEPUTADOS E AGENDA FEMINISTA: IMPACTOS DA ONDA CONVERVADORA SOBRE O PERFIL DAS ELEITAS
}

\author{
ANALYSIS OF FEMALE REPRESENTATION IN THE CHAMBER OF DEPUTIES \\ AND THE FEMINIST AGENDA: IMPACTS OF THE CONVERVATIONAL WAVE \\ ON THE PROFILE OF THE ELECTED
}

\author{
Deise Birk Fernandes ${ }^{1}$ \\ Alessandro Fernandes ${ }^{2}$
}

\begin{abstract}
RESUMO: O presente trabalho pretende analisar o conceito de Feminismo no Brasil nos anos 1970, e seu impacto na resistência ao governo militar $1964 \mathrm{e}$ busca ainda relacionar de que forma essa atuação teve reflexos no processo de redemocratização e na participação das mulheres na Câmara dos Deputados, além de demonstrar a mudança de características na representação feminina em função da onda conservadora que invadiu o país no movimento que culminou com a eleição de Jair Bolsonaro, alterando as pautas e os partidos majoritários na composição da bancada feminina. Para tanto analisamos o protagonismo de políticas na participação da administração pública direta e composição das bancadas partidárias da Câmara dos Deputados na legislatura 2019-2022. Concluímos pela necessidade de valorização das pautas feministas na condução de uma agenda progressista, em especial em partidos do campo democrático e popular.
\end{abstract}

Palavras- Chaves: Feminismo. Representação Política. Onda conservadora.

\footnotetext{
${ }^{1}$ Mestranda em Educação pela Universidade do Vale do Rio dos Sinos. Possui graduação em Licenciatura em Pedagogia pela Universidade do Vale do Rio dos Sinos. Especialização em Direito Educacional e Gestão Escolar pela Faculdade Venda Nova do Imigrante. Especialização em Mídias na Educação pelo Instituto Federal de Educação Ciência e Tecnologia Sul-rio-grandense. Especialização em Educação Especial pela Faculdade Venda Nova do Imigrante. Especialização em Inovação e Empreendedorismo para Negócios Sustentáveis no Instituto Federal de Mato Grosso. Especialização em Impactos da Violência na Educação pela Fundação Oswaldo Cruz. Especialização em Gestão Pública Municipal pela Universidade Federal do Rio Grande. Especialização em Educação para Direitos Humanos pela Universidade Federal do Rio Grande. ORCID https://orcid.org/oooo-ooo3-1270-5983

2 Mestre em Gestão em Negócio pela Universidade do Vale do Rio dos Sinos. Pós-Graduando em MBA em Direito do Agronegócio pela Faculdade Legale. Pós-Graduação Lato Sensu em Gestão de Risco e Cibersegurança pela Faculdade Focus. Pós-Graduação Lato Sensu em Lei Geral de Proteção de Dados pela Faculdade Legale. Pós-Graduação Lato Sensu em História da Guerra pela Faculdade Venda Nova do Imigrante. Pós-Graduação Lato Sensu em Educação em Direitos Humanos pela Universidade Federal de Rio Grande. Pós-Graduação Lato Sensu em Direito Público para Faculdade Legale. Pós-Graduação Lato Sensu em Gestão Pública Municipal pela Universidade Federal de Rio Grande. Pós-Graduação Lato Sensu em Inovação e Empreendedorismo em Negócios Sustentáveis pelo Instituto Federal de Mato Grosso. Pós-Graduação Lato Sensu em Compliance pela Faculdade Venda Nova do Imigrante. Pós-Graduação Lato Sensu em Gestão Estratégica em Políticas Públicas pela Universidade Estadual de Campinas. MBA em Agronegócios pela Faculdade UniCesumar. PósGraduação Lato Sensu em Direito Empresarial pela Universidade do Vale do Rio dos Sinos. Bacharel em Ciências Jurídicas e Sociais pela Universidade do Vale do Rio dos Sinos. cursando Licenciatura em História pela Universidade Federal de Pelotas (2024). ORCID: https://orcid.org/oooo-00o2-0356-2565.
} 


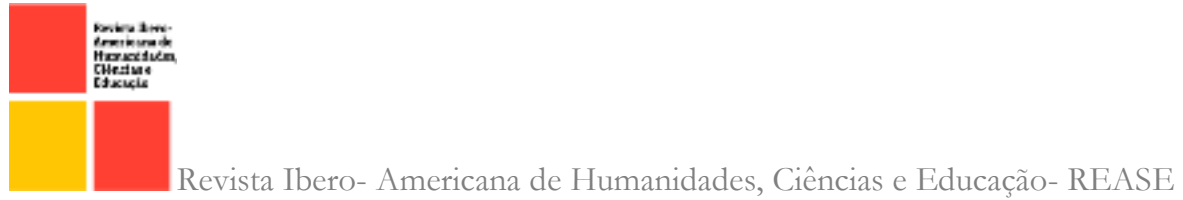

ABSTRACT: This paper intends to analyze the concept of Feminism in Brazil in the 197os, and its impact on the resistance to the 1964 military government, and also seeks to relate how this action had an impact on the redemocratization process and on the participation of women in the Chamber of Deputies, in addition to to demonstrate the change in characteristics of female representation due to the conservative wave that invaded the country in the movement that culminated in the election of Jair Bolsonaro, changing the agendas and the majority parties in the composition of the female bench. To do so, we analyze the role of policies in the participation of direct public administration and composition of party caucuses of the Chamber of Deputies in the 2019-2022 legislature. We conclude that there is a need for valuing feminist agendas in conducting a progressive agenda, especially in parties in the democratic and popular fields.

Keywords: Feminism. Political Representation. Conservative wave.

\section{INTRODUÇÃO}

O presente trabalho pretende analisar o conceito de Feminismo no Brasil nos anos 1970, e seu impacto na resistência ao governo militar 1964 e busca ainda relacionar de que forma essa atuação teve reflexos no processo de redemocratização e na participação das mulheres na Câmara dos Deputados.

Superada esta análise tentaremos ainda demonstrar a mudança de características na representação feminina em função da onda conservadora que invadiu o país no movimento que culminou com a eleição de Jair Bolsonaro, alterando as pautas e os partidos majoritários na composição da bancada feminina.

\section{FEMINISMO E LIBERALISMO POLÍTICO}

De forma quase unânime, ao ouvir os termos "liberal", "democrático" e "liberal-democrático" proferidos nos meios político ou jornalístico, as pessoas encontram dificuldade em compreender seu real significado (BOBBIO, 2006), e acabam por confundi-los, afinal a expressão liberalismo assume diferentes conotações de acordo com o país que é tratado, passando de um radicalismo de esquerda nos EUA até posições mais centristas em países europeus (BOBBIO et al., 2008, p. 688). Já na América Latina o liberalismo nos remete a um sentimento conservador, vinculado as políticas implementadas na América Latinas desde as décadas de 1980 e 1990 e nos dias atuais, impulsionados pelos ensinamentos do economista norte-americano Milton Friedman, em contraponto a outras versões do liberalismo, especialmente das políticas keynesianas, constituintes do chamado Estado de Bem-Estar Social (DEITOS, 2007; FRIEDMAN, 2017). Este conceito de liberalismo, que se confunde com conceitos de 
neoliberalismo amparados nas lições do Consenso de Washington ${ }^{3}$ e implantada na ditadura chilena pelo Chicago Boys ${ }^{4}$, caracterizada pela excessiva valorização do individualismo (GUERRA, 1998), característica usada para desqualificá-lo, e por consequência também o feminismo liberal (STOLZ, 2013). No Brasil o atual papa do liberalismo é o Ministro da Economia Paulo Guedes's, fortalecendo a imagem do liberalismo brasileiro como alguém com valores liberais na condução econômica mas conservador na pauta dos costumes.

Ainda podemos encontrar conceitos que trabalham o chamado liberalismo jurídico, aquele que se preocupa principalmente com a garantia de direitos individuais (STOLZ, 2013) e o liberalismo político, que se manifesta com mais força no sentido da luta política parlamentar (BOBBIO et al., 2008, p. 688), o qual irei concentrar-me neste estudo, principalmente por, como vamos melhor especificar posteriormente, ao contrário dos movimentos feministas europeus que buscavam uma revitalização após o sucesso da luta pelo direito ao voto com o movimento Sufragistas (STOLZ, 2003), esta era a maior bandeira de mobilização das forças populares dos anos 1970, não se limitando a pauta dos movimentos feministas.

\section{DA RESISTÊNCIA AO GOLPE MILITAR AO CRESCIMENTO DA ONDA CONSERVADORA}

A participação dos movimentos feministas na contestação ao golpe militar de $\mathrm{I}^{\circ}$ de abril de 1964 é um movimento natural, considerando o feminismo sempre postou no flanco progressista das teorias liberais (JAGGAR in STOLZ, 2003). Assim a gênese do feminismo brasileiro dos anos 1970 foi impactada pela contestação à ordem política instituída no país naquele momento (SARTI, 2004).

3 Consenso de Washington foi o nome dado pelo economista John Williamson, em 1989, a uma lista de dez recomendações dirigidas aos países dispostos a reformar suas economias, em especial na América Latina (MALAN, 1991).

4 Grupo de economistas oriundos da Escola de Economia de Chicago que conduziu uma política destinada a estabilizar o nível de preços, mas fora isso, eles inseriram reformas que buscaram dar ao mercado um papel maior na regulação da vida econômica do país, sendo responsáveis por tornar o Chile o primeiro país a seguir a doutrina neoliberal (LIRA, 2010).

5 Nas vésperas da eleição de 2018 seu perfil na revista Piaúí teve o seguinte subtítulo "a trajetória e as polêmicas do economista Paulo Guedes, o ultraliberal que se casou por conveniência com Jair Bolsonaro". Este perfil ainda resgata o apelido que recebeu dos economistas do governo Sarney, pela contundência e pelo catastrofismo de seu discurso, Beato Salu, o personagem da novela Roque Santeiro que perambulava pela cidadezinha de Sinhozinho Malta e viúva Porcina anunciando o fim do mundo. (GASPAR, 2018). 


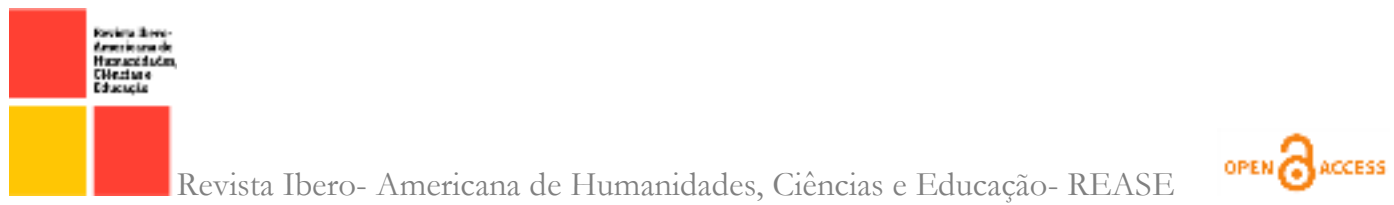

Já em 1968, entre os detidos no Congresso da UNE de Ibíuna ${ }^{6}$ encontravamse cerca de duzentas estudantes, demonstrando sua importância para resistência ao governo, ainda fora da clandestinidade e da lua armada (GARCIA, 2010; PALMAR, 2012). Com a radicalização da oposição ao governo militar, partindo para a luta armada, o movimento feminista acabou também radicalizando e tomando a opção por armas. Dos setenta e oito "mortos em combate" na Guerrilha do Araguaia" dezesseis eram de mulheres combatentes, ligadas ao PCdoB (MORAIS, SILVA, 2005). Da mesma forma na guerrilha urbana as mulheres ocuparam posição de destaque, gerando inclusive a Torre das Donzelas ${ }^{8}$, contrariando Svetlana Aleksiévitch (2016) que nomeou sua obra com o título "a guerra não tem rosto de mulher".

Sarti (2004, p. 36) reforçava que, em que pese a influência das experiências européias e norte-americana, o início do feminismo brasileiro dos anos 1970 foi significativamente marcado pela contestação ao golpe militar de 1964, com parte expressiva dos grupos feministas em articulação com as organizações de influência marxista, clandestinas à época. Esta participação, tanto na guerrilha urbana como nos focos maoistas, implicou não somente na insurgência contra a ordem política vigente, mas representou uma profunda transgressão ao que era designado à época como próprio das mulheres (SARTI, 2004, p. 37).

Porém, com o processo de redemocratização via Colégio Eleitoral e a ascensão de Sarney (ex-presidente da ARENA) a Presidência, não ocorreu uma valorização do movimento feminista no novo Governo.

Da mesma forma durante o Governo Collor a pauta feminista não teve nenhuma relevância. Em que pese a importância da Figura da Ministra da Fazenda, Zélia Cardoso, logo triturada pelo fracasso do Plano Collor, e sua presença no governo não representava qualquer avanço para pauta feminista, uma vez que não dialogava com este movimento.

6 30을 Congresso da União Nacional dos Estudantes (UNE) realizado em Ibiúna no interior do Estado de São Paulo, detendo cerca de 900 estudantes, incluindo Luís Travasso, Vladimir Palmeira e José Dirceu principais líderes dos protestos estudantis de maio de 1968 (DIRCEU, PALMEIRA, 1998).

7 Guerrilha do Araguaia foi um movimento guerrilheiro, de inspiração Maoista, existente na região amazônica brasileiro entre o final dos anos até ser desmantelada em 1973 pela repressão do Governo Militar (GASPARI, 2015). 8 Torre das Donzelas era o apelido da ala feminina do Presídio Tiradentes, que ficava na região Central de São Paulo, e onde as mulheres detidas pela ditadura ficavam encarceradas, onde o então major Carlos Alberto Brilhante Ustra, comandante do DOI-Codi, costumava comandar suas sessões e tortura (ESCOREL, 2019). O voto do então Deputado Federal Jair Bolsonaro no processo de impeachment de Dilma Rousseff, uma das detentas da torre, ao homenagear Ustra serviu de uma homenagem a tortura e o desrespeito aos direitos humanos, que não surpreendia quem já conhecia sua carreira parlamentar. 
No governo Itamar a indicação da então petista Luíza Erundina (ela rompeu com o seu partido em função da decisão de integrar a oposição ao novo governo) representava um espaço de interlocução, ainda que limitado, com os movimentos feministas.

Nos dois mandatos de FHC nenhuma mulher ocupou papel de destaque no ministério, porém, a socióloga e primeira-dama (termo que ela tinha ojeriza) Ruth Cardoso representou um papel importante na consolidação de uma pauta progressista (para os padrões tucanos).

A posse do Governo Lula contrariou esta lógica. Em que pese o protagonismo do primeiro mandato ter sido inicialmente disputado pelos Ministros Zé Dirceu e Antônio Palocci, era representativo o espaço das ministras, quase todas com interlocução com os movimentos populares, destacando-se a presa política da Torre das Donzelas e ex-militante da VPR, Dilma Rousseff. A prática política diz que a proximidade do poder na foto de posse não é somente simbólica. Lula encontra-se ladeado por seu vice José de Alencar e pela Ministra Dilma, demonstrando claramente sua importância e influência no governo.

Figura r: Posse de Lula e Ministros (segundo mandato)

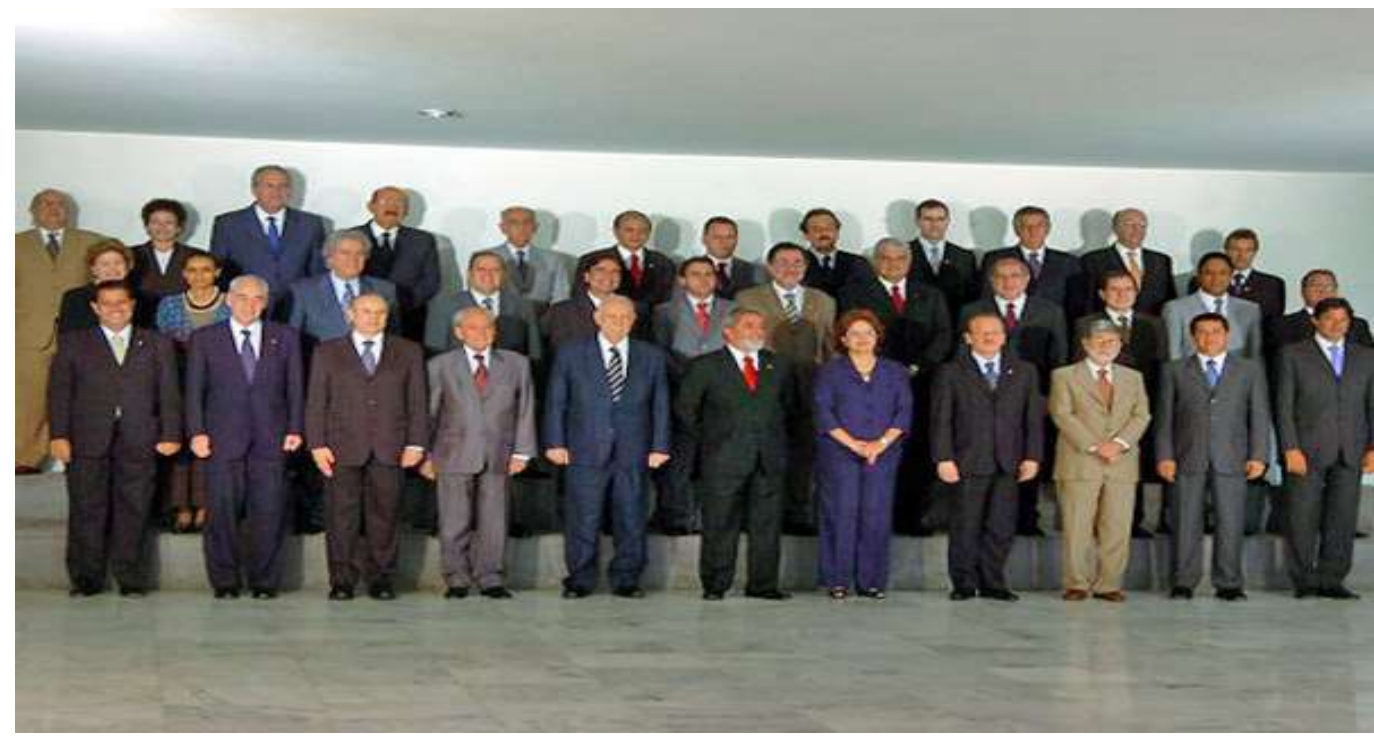

Fonte: Roosewelt Pinheiro/Agência Brasil. Disponível em https://glo.bo/2PLWZnw. Acesso em 04 ago. 2020 .

Em seu segundo mandato além da Presidenta, a foto de posse constava com seis mulheres, um recorde, todas comprometidas com as pautas feministas. Porém, os 
sorrisos desta foto escondiam as cicatrizes de um processo eleitoral traumático, onde o derrotado, Aécio Neves, contestou os resultados e serviu de fagulha para incendiar um processo que culminou em uma crise econômica ${ }^{9}$ e política.

Figura 2: Posse de Dilma e Ministros (segundo mandato)

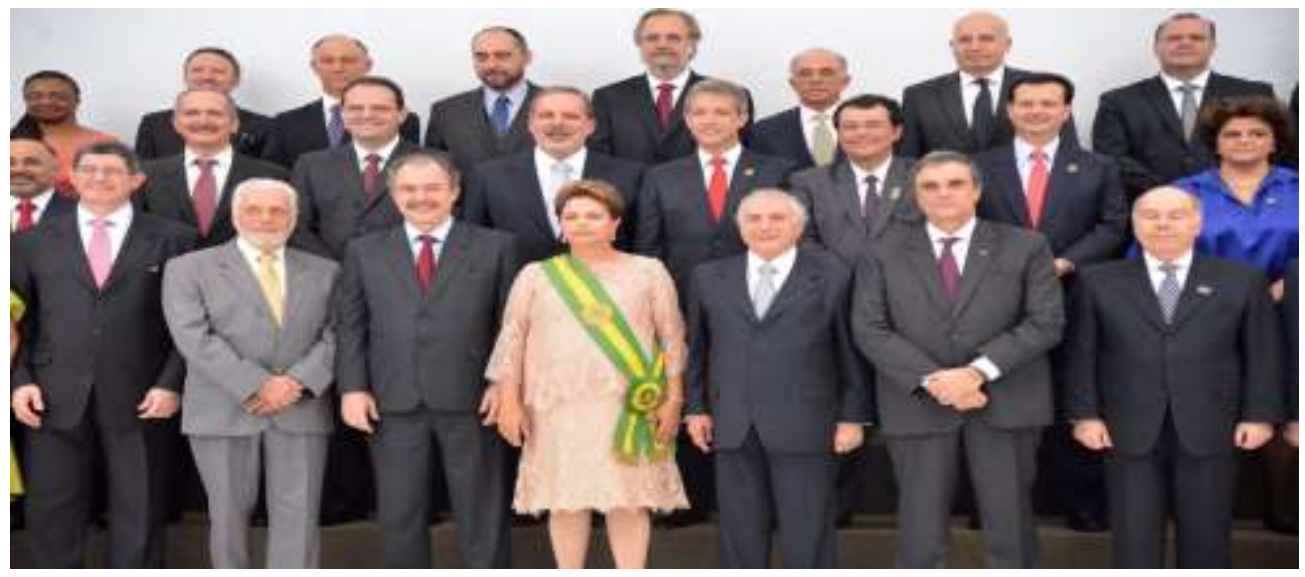

Fonte: Roberto Stuckert Filho/PR. Disponível em https://bit.ly/2wrTRqf. Acesso em I4 ago. 2020.

O sorridente vice aproveitou-se dessa fragilidade para, em conluio com seu correligionário Presidente da Câmara dos Deputados Eduardo Cunha, comandar um processo de Impeachment baseado em uma pedalada fiscal, sem imputação de qualquer crime a afastada. Em sua posse, sem fotos e cerimônias, foi empossado um ministério formado somente por homens brancos.

Figura 3: Michel Temer empossa o Ministério

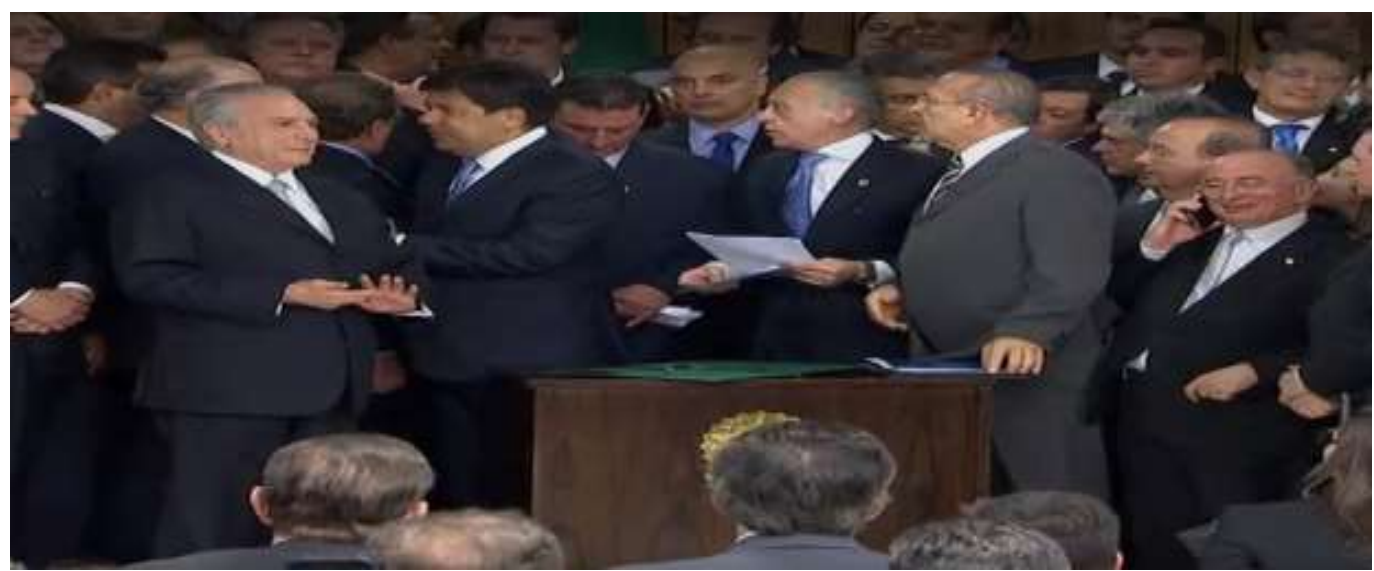

Fonte: Reprodução/NBR. Disponível em https://glo.bo/3aqwstu. Acesso em I9 ago. 2020.

9 Produto Interno Bruto (PIB) não serve de indicador de desenvolvimento econômico, servindo somente como termômetro do crescimento econômico, que só teria razão de ser se for sustentável, sustentado e includente (SACHS, 2004). 
Infelizmente este golpe branco teve como resultado o fortalecimento da onda conservadora, que acabou culminando com a eleição daquele que usou seu mandato parlamentar para homenagear um torturador ${ }^{\mathrm{io}}$ : Jair Messias Bolsonaro.

Figura 4: Posse de Bolsonaro e Ministros

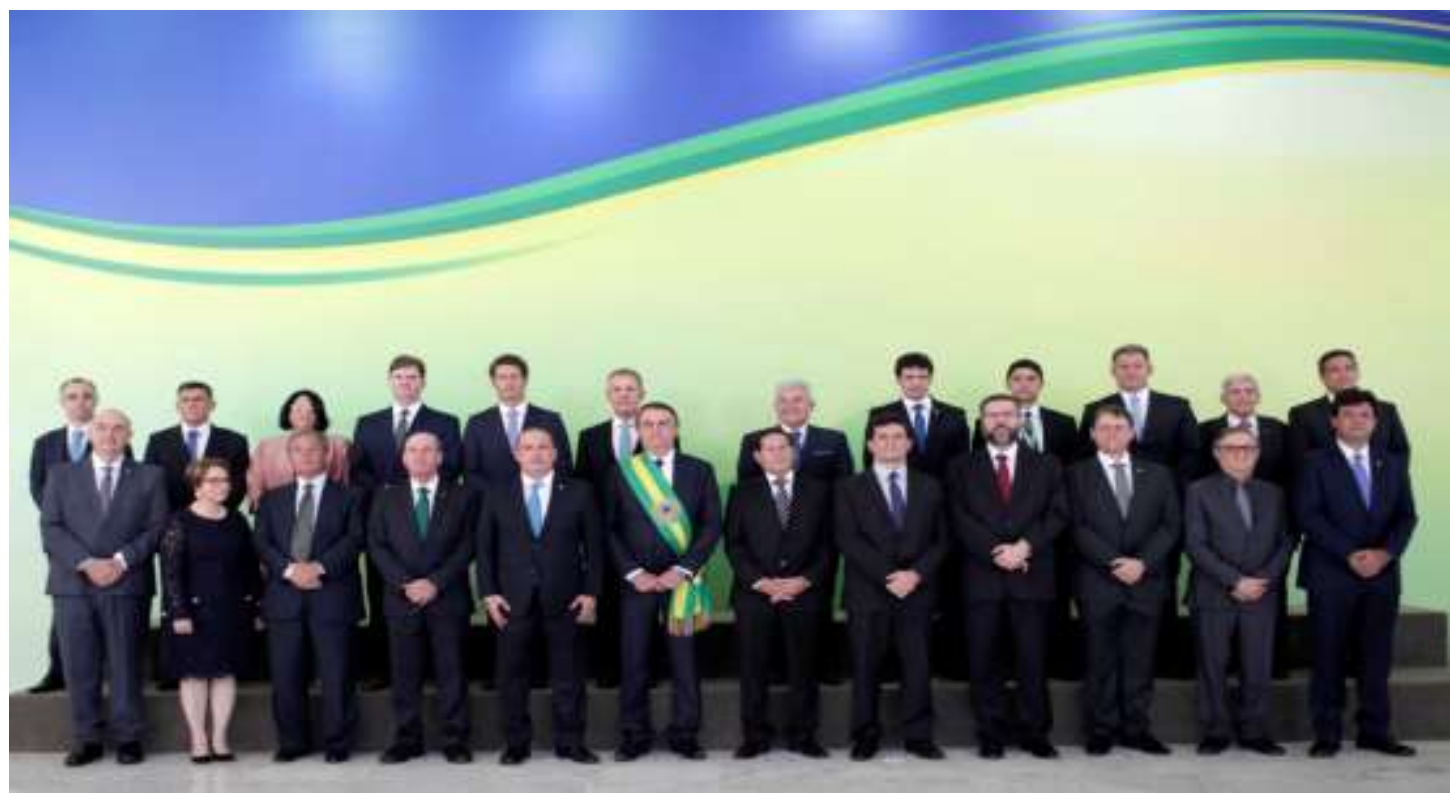

Fonte: Ueslei Marcelino/Reuters. Disponível em https://glo.bo/2uPrvWq. Acesso em i9 ago. 2020.

$\mathrm{Na}$ foto de Bolsonaro percebe-se a presença de apenas duas mulheres, a conservadora Damares Alves e a Deputada Tereza Cristina, indicada pela Bancada Ruralista $^{\mathrm{II}}$, na tentativa (aparentemente frustrada) de romper com o Presidencialismo de Coalizão ${ }^{\mathrm{I2}}$.

\section{FEMINISMO: REPRESENTAÇÃO PARLAMENTAR}

Em decorrência de sua origem, junto as lutas de esquerda, o movimento feminista sempre teve maior vinculação dos partidos do espectro Democrático Popular

Io O ex-chefe do DOI-Codi Carlos Alberto Brilhante Ustra foi o primeiro militar brasileiro a responder processo por crime de tortura durante a ditadura militar, sendo condenado em segunda instância por este crime(CAETANO, 2019).

II No início da legislatura anterior ( $55^{\text {a }}$ Legislatura 2015-2019), ao analisar o crescimento do número de deputados conservadores na Câmara dos Deputados, foi cunhada a expressão bancada BBB, com as iniciais bíblia, boi e bala (ROCHA, 20I5). Essas três bancadas, a saber, a da "bala" formada pelos deputados com atuação na área da segurança pública, a da "bíblia" formada pelos parlamentares ligados as mais variadas representações religiosas e o "boi" é representado pelos parlamentares integrantes da Frente Parlamentar da Agropecuária (FPA), nome oficial da conhecida bancada ruralista.

12 A opção por governos de coalizão foi feita por todos os governos federais no período pós-I989. Nesta modalidade de governo, os espaços governamentais (ministérios e estatais) são distribuídos de forma proporcional ao tamanho das bancadas partidárias dispostas a apoiar os projetos de interesse do governo e, principalmente, rejeitar propostas ou investigações contrárias aos seus interesses (ABRANCHES, 2018). 
(PT, PSOL, PCdoB, PDT, PSB, REDE). Já se notava que nem toda representação feminina no Congresso derivava do movimento feminista sendo comum, principalmente nos partidos $\mathrm{MDB}, \mathrm{PP}$ e PSDB, representação feminina de tradicionais oligarquias, como filhas ou esposas de caciques locais.

No Estado do Mato Grosso (MT), por exemplo, dos 8 Deputados Federais nas últimas 3 legislaturas ${ }^{13}$ a única Deputada Federal eleita foi Teté Bezerra, esposa do cacique Carlos Bezerra, enquanto a única representante feminina era Janaína Riva, herdeira política de José Riva, preso em megadelação pantaneira enquanto todas as 25 cadeiras da Câmara Municipal de Cuiabá são ocupadas por parlamentares homens. Mesmo assim, percebeu-se um crescimento de bancadas femininas de perfil conservador, negando inclusive o movimento feminista, capitalizado pelo crescimento da bancada do PSL (GALVANI, 2019).

Gráfico r: Deputadas Federais empossadas em 31 jan. $2019^{14}$

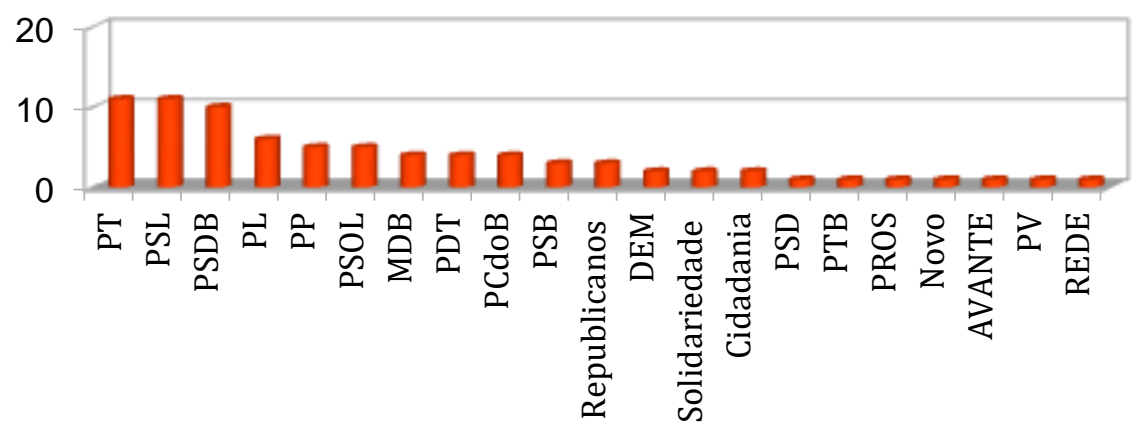

Deputadas Eleitas

Fonte: Disponível em https://bit.ly/2vD36Er . Acesso em 24 ago. 2020.

Claro que a distribuição somente pelo número de cadeiras na Câmara dos Deputados pode sofrer distorções na comparação das bancadas, e em consequência das pautas representadas nesta Casa Legislativa. As doze cadeiras do PSL parecem mais relevantes que as cinco cadeiras do PSOL ou ainda a única representante feminina eleita pela REDE, porém quando comparadas com as bancadas totais eleitas por partido

13 Nesta legislatura foi eleita para uma cadeira de Deputada Federal a Professora Rosa Neide (PT), sem qualquer influência familiar em sua eleição e vinculada a pautas com relação ao movimento feminista. Para o Senado foi eleita, em discurso aderente ao de Jair Bolsonaro, a Juíza Selma (PSL), já cassada por abuso de poder econômico. Cidadania ainda possuía o registro junto ao TSE como PPS em 3r jan. 2019. 
percebe-se a importância da representação feminina nos partidos do campo democrático e popular. O gráfico abaixo deixa mais clara a proporção na representação.

Gráfico 2: Proporção entre Deputadas e Deputadas empossados em 31 jan. 2019 por partido $^{\text {I5 }}$

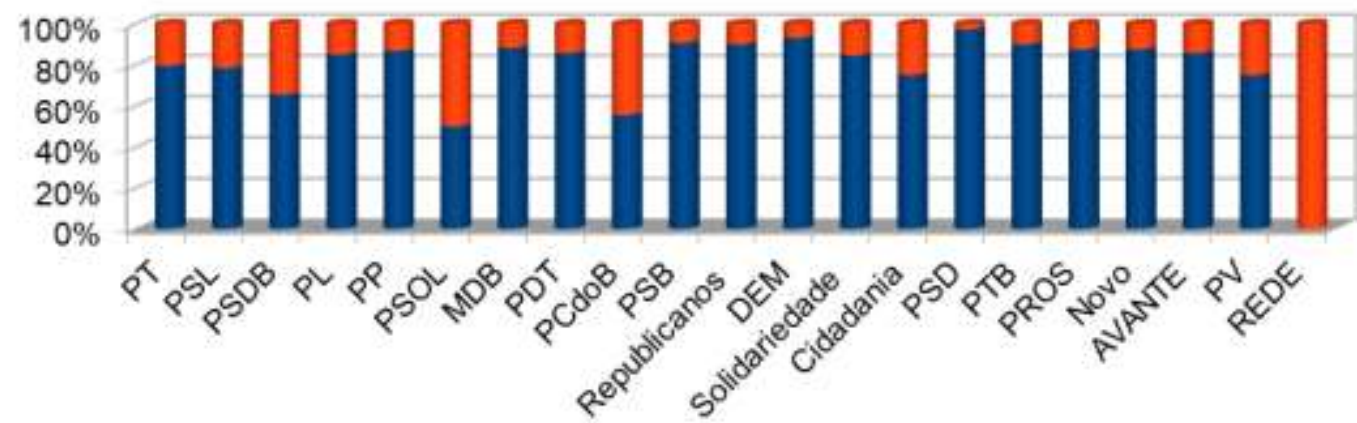

-Deputados Eleitos = Deputadas Eleitas

Fonte:Disponível em https://bit.ly/3csbney. Acesso em 24 ago. 2020.

Percebe-se a maior distribuição na proporção entre Deputados e Deputadas eleitas nos partidos PSOL e $\mathrm{PCdoB}^{\mathrm{16}}$, normalmente vinculados as pautas feministas. Chama ainda atenção a baixa proporção de Deputadas eleitas pelo PSB e a queda de representação feminina (e baixíssima renovação dos quadros) na bancada do PT, que em legislaturas passadas protagonizava a discussão de pautas progressivas. Nesta legislatura a proporção de Deputadas eleitas pelo PT é o mesmo do PSL e inferior ao PPS e ao PSDB, demonstrando uma necessidade de reavaliação (ou até mesmo refundação) de seu processo de formação de quadros.

\section{CONCLUSÃO}

Em que pese o avanço da representação feminina na agenda política nacional percebe-se uma necessidade de valorização das pautas feministas na condução de uma agenda progressista, em especial em partidos do campo democrático e popular. É comum a busca de representantes femininas para completar a lista de candidatas proporcionais, em função da legislação eleitoral, ou ainda, em função da capacidade de

I5 Desconsideramos neste gráfico as bancadas dos partidos PTC, PODEMOS, PMN, Patriota, DC, PPL, PRP e PSC que não elegeram nenhuma Deputada Federal na eleição de 2018.

i6 O fato de a REDE ter eleito somente um representante em todo o país acaba prejudicando conclusões em cima de sua proporção. 
agregar votos, para ocupar a função de vice em uma chapa majoritária, mas não se tem mais um trabalho de formação e renovação de seus quadros. Além do mais, existe uma forte carga de machismo (e de homofobia) na esquerda latino-americana, baseada no caudilhismo, o que impede um protagonismo de pautas feministas e surgimento de novas lideranças.

Creio que a lição do PSOL e PCdoB deveria ser seguido pelos partidos hegemônicos do campo democrático e popular. O primeiro tem formado quadros junto aos movimentos populares, valorizando as pautas femininas e das pautas LGBTs enquanto o segundo tem focado sua atuação principalmente junto ao movimento estudantil.

\section{REFERÊNCIAS}

ABRANCHES, Sérgio. Presidencialismo de Coalizão. Rio de Janeiro: Companhia das Letras. 2018. $440 \mathrm{p}$.

BOBBIO, Norberto. METTEUCCI, Nicola. PASQUINO, Gianfranco. Dicionário de política. Brasília, São Paulo: UnB. 2008. 2 vol. 1330 p.

BOBBIO, Norberto. Liberalismo e democracia. São Paulo: Brasiliense. 2006. I44 p.

CAETANO, Guilherme. Condenado por tortura na ditadura militar, Ustra segue poupado por segmentos da direita. O Globo. o8 ago. 2019. Disponível em: https://bit.ly/2VYEINe>. < Acesso em o9 ago. 2020.

DEITOS, Roberto Antônio. Liberalismo educacional: o receituário de Milton Friedman. Ciências Sociais em Perspectiva, vol.6, n. Io: 2007, pp.137-I47.

DIRCEU, José. PALMEIRA, Vladimir. Abaixo a ditadura. Rio de Janeiro: Garamond. 1998. $196 \mathrm{p}$.

ESCOREL, Eduardo. Torre das Donzelas: alerta de um passado remoto. Revista Piauí. Set. 2019. Disponível em: 〈https://bit.ly/2wAfnJj〉. Acesso em is ago. 2020.

FRIEDMAN, Milton. Capitalismo e liberdade. LTC; Ed. I, 2017. 286 p.

GALVANI, Giovanna. Entre feministas e conservadoras, Bancada Feminina luta pela sobrevivência. Carta Capital. 13 set. 2019. Disponível em: 〈https://bit.ly/381N $3 \mathrm{HZ}\rangle$. Acesso em 23 ago. 2020.

GASPAR, Malu. O Fiador. Revista Piauí. Ed. 144, Set. 2018. Disponível em: $\langle$ https://bit.ly/3aqVC 5 H〉. Acesso em 24 ago. 2020. 
GASPARI, Élio. Ditadura Derrotada Intríseca. 2015. 580 p.

GUERRA, Roberto Rodríguez. El liberalismo conservador contemporáneo. La Laguna: Servicio de Publicaciones, Universidad de La Laguna, 1998. 266 p.

GARCIA, Priscila Fernanda da Costa. As meninas de Ibiúna, militantes e oprimidas: mulheres e esquerda no congresso estudantil de 1968. Grupo de Estudos de Política da América Latina. Anais do IV Simpósio Lutas Sociais na América Latina. Grupo de Trabalho Feminismo e Marxismo na América Latina. Londrina: UEL. Set. 2010.

LIRA, Francisco Roberto Fuentes Tavares de. Do socialismo ao neoliberalismo: o Chile dos anos 1970. Curitiba: Vitrine da Conjuntura. V.3,n.6, ago. 2010. pp. I-9.

MALAN, Pedro Sampaio. Uma crítica ao Conceito de Washington. Revista de Economia Política, vol. II, n. 3 (43), jul./set. I99I, p. 5-12.

MORAIS, Taís. SILVA, Eumano. Operação Araguaia: os arquivos secretos da Guerrilha. Geração Editorial. 2005. II97 p.

PALMAR, Aluízio. Mulheres de Ibiúna: apresentação com fotos e informações das mulheres que participaram do Congresso da UNE, em 1968. Foz do Iguaçu: Ed. Grampo. 16 mar. 2012. Disponível em: 〈https://bit.ly/2IkXRLY〉. Acesso em is ago. 2020.

ROCHA, Leonel. “Aumenta a bancada BBB: bíblia, boi e bala”, diz Erika Kokay. Revista Época: coluna Felipe Patury. 04 fev. 2015.

SACHS, Ignacy. Desenvolvimento Includente, Sustentável e Sustentado. Garamond. 2004. $152 \mathrm{p}$.

SARTI, Cynthia Andersen. O feminismo brasileiro desde os anos 1970: revisitando uma trajetória. Revista Estudos Femiminista. 2004, vol.12, n.2, pp.35-50.

STOLZ, Sheila. Teorias Feministas Liberal, Radical e Socialista: vicissitudes em busca da emancipação das mulheres. In STOLZ, Sheila; MARQUES, Clarice Pires, MARQUES, Carlos Alexandre M. (Org.). Cadernos de Educação em e para os Direitos Humanos: Diversidades nos Direitos Humanos. Rio Grande: Editora da FURG. 2013, pp. 29-50. 